\title{
Valores para mi País: Evangélicos en la Esfera Política Argentina (2008-2011)
}

\author{
Marcos Carbonelli
}

Consejo Nacional de Investigaciones Científicas y Técnicas (Conicet), Buenos Aires, Argentina. E-mail: m_a.carbonelli@yahoo.com.ar

\section{INTRODUCCIÓN}

$\mathrm{E}$ n la década de 1990, la participación partidaria evangélica en Argentina se encontró marcada por la experiencia de partidos que reivindicaron una pertenencia y representación evangélica en competencias electorales ${ }^{1}$. En 1993, pastores y líderes pentecostales del Gran Buenos Aires conformaron el Movimiento Cristiano Independiente (MCI), que participó en las elecciones de generales de 1993 y 1995, además de la convocatoria a la Asamblea Constituyente en 1994. El Movimiento Reformador Independiente (MRI) fue la expresión de esta misma fuerza política en la provincia de Córdoba. Las propuestas de ambas agrupaciones consistía en "redimir y reconstruir lo político", en tanto esfera contaminada por el pecado, a partir de la aplicación de principios extraídos del Antiguo Testamento. Sus dirigentes procuraban afianzar sus bases electorales en las congregaciones evangélicas, por medio de la organización de campañas en los templos y presentándose como portadores de una misión complementaria a la de los especialistas religiosos.

Tras registrar severas derrotas en los comicios citados ${ }^{2}$, una fracción del MCI fundó el Movimiento Reformador (MR), el cual abandonó el formato de partido confesional y apostó por una política de alianzas, comportándose como un espacio evangélico al interior de estructuras políticas "seculares". También ponderó una nueva identidad, de caDADOS - Revista de Ciências Sociais, Rio de Janeiro, vol. 58, no 4, 2015, pp. 981 a 1015. 
rácter más populista, incorporando ideas como la búsqueda de la justicia social, la lucha contra la corrupción y la reivindicación de los intereses del pueblo. La afinidad de este ideario con la tradición peronista facilitó su acercamiento con dirigentes que abandonaban la estructura del Partido Justicialista, dirigida por el entonces presidente y líder del partido Carlos Menem por considerar que sus políticas neoliberales contradecían sus doctrinas históricas (Ollier, 2001:41). Bajo esta perspectiva, los miembros del MR integraron formaciones políticas "disidentes" como el Frepaso (Frente para un País Solidario) en 1995, la Democracia Cristiana en 1997, y por último, el Polo Social dirigido por el sacerdote católico Luis Farinello en el período 2000-2001 (Wynarczyk, 2010:325).

Wynarczyk (2010) y Semán (2000) señalan que las proyecciones políticas de estos grupos fracasaron porque no pudieron desarrollar una modalidad de interpelación política que quebrara el lazo de afinidad establecido entre los sectores populares del Gran Buenos Aires e identidades políticas tradicionales, incluido el peronismo, cuyo discurso y estructura oficial seguía en manos del menemismo. Wynarczyk añade que los dirigentes de los partidos confesionales fueron cuestionados por las federaciones y pastores porque consideraban que sus estrategias de movilización en los templos conducirían a la partidización y consiguiente faccionalización de las comunidades (2006:35).

Tanto en lo que refiere a su agenda como a sus referentes, estas incursiones partidarias no estuvieron vinculadas con la movilización por una nueva ley de cultos, la causa política evangélica más importante de la década (Wynarczyk, 2009). Dicha acción fue protagonizada por las federaciones Alianza Cristiana de Iglesias Evangélicas de la República Argentina (Aciera), la Federación Argentina de Iglesias Evangélicas (FAIE) y la Federación Confederación Evangélica Pentecostal (FeCEP), quienes iniciaron presentaciones formales ante los diferentes gobiernos para gestionar un nuevo estatus jurídico, al mismo tiempo que visibilizaron su protesta en las concentraciones en el Obelisco en septiembre de 1999 y de 2001.

Este artículo propone retomar el abordaje de las intersecciones entre lo partidario y lo evangélico, a partir del estudio de caso del partido Valores para mi País (VPMP), entre 2008 y 2011. Varios elementos permiten nominar a VPMP como la experiencia partidaria evangélica más importante del nuevo milenio en Argentina. En primer lugar, porque fue 
fundada por Cynthia Hotton, una referente que alcanzó uno de los cargos públicos más relevantes en la historia de las trayectorias evangélicas en política ${ }^{3}$, y con un nivel de visibilidad mediática inédito. En segundo término, porque en el itinerario político de VPMP se anudaron la demanda de la ley de cultos y la proyección partidaria, dos ejes que como ya señalamos, se encontraron desconectados en la década de 1990. Finalmente, porque, a partir de la presentación de demandas alineadas con posicionamientos ortodoxos en cuestiones de moral sexual y de un discurso crítico de la corrupción, VPMP pretendió interpelar no sólo a la comunidad evangélica, sino también a otras audiencias o públicos religiosos, adquiriendo la novedosa figura de partido pluriconfesional y post-ideológico. Las particularidades del caso y la repercusión de sus demandas nos permitirán reflexionar sobre la potencialidad política de los emprendimientos evangélicos en la Argentina contemporánea, asumiendo como puntos de partida la histórica subordinación de esta minoría en la definición social de lo religioso (Giumbelli, 2002), y la ausencia de una base electoral propia, es decir, la inexistente gravitación en Argentina de un "voto evangélico", tal como ocurre en Brasil.

El foco del artículo reside tanto en las iniciativas políticas de VPMP (propuestas, demandas y críticas) como en sus estrategias de posicionamiento en el mundo partidario y religioso (capitales puestos en juego y definición de aliados y adversarios en ambas esferas). El análisis de estas dos dimensiones - identitaria y estratégica - nos permitirá reconstruir la apuesta representativa de VPMP, es decir, su propuesta de interpelar y movilizar a diferentes públicos para constituirse en su legítimo representante. Dicha apuesta representativa admite la variación temporal como rasgo constitutivo. En otras palabras: asumimos que el trabajo sobre el lazo representativo muta en el tiempo, cambia de formato, "se corrige sobre la marcha", porque se ancla en los monitoreos reflexivos que los líderes efectúan sobre sus proyectos partidarios, y evalúa permanentemente sus alcances en un contexto electoral. Bajo esta perspectiva, enfatizaremos en nuestro análisis los ajustes registrados en la apuesta representativa de VPMP en sucesivas etapas, sustentados a su tiempo en el impacto público-partidario de las acciones de su referente.

Adoptaremos una modalidad de análisis cronológica, bajo la cual delinearemos la inserción partidaria de Hotton y el proceso de fundación de VPMP. Luego profundizaremos sobre la intervención de la diputa- 
da en tres controversias públicas, estrechamente conectadas con los marcadores identitarios de su agrupación: el debate legislativo en torno al matrimonio entre personas del mismo sexo (abril-junio de 2010), la presentación del nuevo proyecto de ley de cultos (abril-agosto de 2010), y la denuncia de intento de soborno en el debate del presupuesto nacional en la Cámara de Diputados (noviembre de 2010). Finalmente, abordaremos la transformación de VPMP en un partido con identidad "cristiana" y la candidatura de Hotton a la Legislatura de la Ciudad de Buenos Aires en 2011. En las conclusiones, sintetizaremos las particularidades de VPMP de cara a sus antecedentes, evaluaremos los alcances de su apuesta representativa y explicitaremos las implicaciones de este caso para los estudios sobre religión y política en Argentina.

En términos metodológicos, seguimos una estrategia mixta que incluye entrevistas en profundidad realizadas en dos ocasiones a Cynthia Hotton (al comienzo y al cierre de su proyección partidaria), asi como tambien diez entrevistas en profundidad y charlas informales efectuadas a referentes de su agrupación. Asimismo, se analiza el contenido de proyectos legislativos de Hotton, sus discursos en la Cámara de Diputados, sus apariciones televisivas y conferencias brindadas en universidades y espacios religiosos, así como documentos publicados por la agrupación en sus espacios digitales y noticias sobre VPMP registradas en la prensa evangélica y en la prensa nacional. Por último, otro insumo fundamental es el relevamiento etnográfico de reuniones y marchas encabezadas por la agrupación en el período 2008-2011.

\section{EL SURGIMIENTO DE VALORES PARA MI PAÍS}

Hotton pertenece a una familia reconocida en el espacio evangélico argentino. Su bisabuelo Jorge Hotton, fue un misionero australiano que evangelizó en el norte de la provincia de Buenos Aires a comienzos del siglo veinte. Su padre, Arturo Hotton, tuvo un rol destacado en la formación de la federación Aciera ${ }^{4}$ y del MCI. Paralelamente, se desempeñó como diplomático y, tras su alejamiento del MCI, se relacionó con el Partido Recrear para el Crecimiento (Recrear) y su principal referente, Ricardo López Murphy. En esta estructura, se postuló como candidato a vicegobernador por la provincia de Buenos Aires en el año 2003, junto a Hernán Lombardi, y obtuvo el séptimo lugar con el 3,97\% de los votos emitidos (Pulso Cristiano 2, 9/10/2003).

La formación profesional y la inserción política de la futura diputada estuvieron marcadas por el legado familiar. En 1991, se recibió de li- 
cenciada en Ciencias Económicas por la Universidad de Buenos Aires. Luego, realizó la Carrera Diplomática en el Instituto del Servicio Exterior de la Nación y fue asesora en el proyecto PNUD (Programa de las Naciones Unidas para el Desarrollo), entre 1992 y 1995, y del CEPAL (Comisión Económica para América Latina y el Caribe) en 1992 y participó en la Dirección de Apoyo a la Promoción del Comercio Exterior, entre 1999 y 2002. Fue asesora en comercio exterior de la Cámara de Diputados y estuvo a cargo del Consulado de Argentina en Salto (Uruguay) en 2004.

Hotton se presentó como candidata a diputada a la legislatura de la provincia de Buenos Aires en las elecciones de 2003 y 2005, sin alcanzar los votos necesarios para acceder a una banca. En las elecciones generales de 2007, Recrear celebró una alianza con el partido Compromiso por el Cambio (CPC), liderado por Mauricio Macri, circunscripta exclusivamente al distrito de la ciudad de Buenos Aires (en la provincia de Buenos Aires los partidos Recrear y CPC mantuvieron sus propias listas de candidatos) $)^{5}$. Para robustecer los avales de su precandidatura en la interna de Recrear (cuyos postulantes luego debían medirse en una segunda interna con los precandidatos de PRO), Hotton intentó sumar adhesiones de pastores y líderes evangélicos, con los que mantenía contacto mediante las redes de Aciera. Lejos de conseguir un apoyo unánime, estos referentes cuestionaron su propuesta de apoyarla bajo el solo argumento de ser "hermana en la fe". Pese a estas desavenencias, Hotton se posicionó finalmente como segunda candidata a diputada nacional. Sin lograr sustentarse en un apoyo evangélico, la obtención del cargo público se fundamentó en un acuerdo entre las cúpulas partidarias, que juzgaron importante la presencia de una mujer en los primeros lugares de la nómina, por atender a las exigencias de la ley de cupo femenino. En las elecciones del 28 de octubre de 2007, el $7,9 \%$ de los votos obtenidos por el PRO en el distrito de Capital Federal le permitió acceder a una banca en la Cámara de Diputados.

Este logro fue resignificado por la diputada como la manifestación de una intervención divina:

Las casualidades muchas veces en política se dan, pero para una persona de fe... yo vi la mano de Dios (...) Y que después hayamos entrado nada más que dos, mi lectura como cristiana fue que el Señor me mostró: "vos, con todo tu esfuerzo, con toda tu militancia, igual, no entrabas. O sea, los tiempos los decido yo". Yo otras dos veces había sido candidata, siempre en segundo lugar y nunca entré. Entonces, Dios da y 
Dios quita, ¿no? Yo en ese momento sentí que había sido la voluntad de Dios que yo haya entrado (Cynthia Hotton, entrevista personal, 10/1/2012).

En esta cosmovisión, la voluntad divina alcanza una dimensión de agencia, bajo la certeza de que lo trascendente delinea el guión de los sucesos políticos, y asigna roles a los creyentes en función de un plan que excede su cognocibilidad. Esta noción de agenciamiento divino también incidió en el diagnóstico sobre la situación del espacio político y en la definición de la participación partidaria en los términos de una "misión".

Pienso decididamente mi identidad como cristiana en la política. Porque los partidos en la Argentina: ser del PRO, del peronismo, del radicalismo no te definen como antes ideológicamente. Hoy los peronistas no oficialistas están más volcados a la derecha, y los de izquierda se encuentran más cercanos a Kirchner. Hoy soy partidaria de jugarme más con mi identidad de cristiana evangélica. Las cosas que decido y las que pienso son a partir de mi identidad como cristiana (Cynthia Hotton, entrevista personal, 6/8/2008).

A partir de un diagnóstico de crisis de las identidades políticas, la adscripción religiosa fue postulada como proveedora de sentido a la acción política frente a la erosión de matrices partidarias históricas, como el peronismo y el radicalismo. Esta visión influyó en la decisión política más importante de Hotton: la creación del espacio político de VPMP y la consiguiente mediatización de su filiación religiosa. Hasta ese momento, esta dimensión identitaria sólo era conocida dentro del mundo de las iglesias y permanecía invisibilizada a los ojos del gran público, los medios de comunicación y la clase política en general. Como veremos a continuación, la fundación de VPMP resultó la piedra de toque de una nueva estrategia, en la que las creencias particulares fueron expuestas intencionalmente por Hotton como la matriz de sentido de su accionar como funcionaria.

El 29 de noviembre de 2008 la diputada convocó una reunión para coordinar su lanzamiento político. El registro etnográfico de este encuentro nos permitió constatar que los convocados fueron fieles de las principales iglesias y mega iglesias pentecostales del Área Metropolitana de Buenos Aires, líderes evangélicos con actuación destacada en el ambiente del marketing empresarial y en la industria del entretenimiento y, finalmente, líderes y pastores que incursionaron en partidos políticos en 
el pasado reciente. Inicialmente fueron reuniones de carácter privado, de acceso restringido a un circuito de contactos privilegiados. Pero a posteriori esta red se amplió intencionalmente a actores posicionados en roles menos jerárquicos del mundo de las iglesias, con la pretensión de extender las bases de sustentación y militancia de la agrupación.

El perfil del espacio político se definió en base a tres ejes: a) la presentación de un nuevo proyecto de libertad religiosa, b) la oposición a la despenalización del aborto y al matrimonio entre personas del mismo sexo y c) la construcción de un discurso anti-corrupción y a favor de la transparencia en las prácticas políticas. Como señala Aboy Carlés (2001:64), una identidad política no se produce en un "vacío discursivo", sino que se constituye en diálogo con discursos, tradiciones y memorias y, a su vez, definiendo figuras antagónicas, que reafirmen (por oposición) las propias fronteras identitarias. En esta perspectiva, las propuestas medulares de VPMP se definieron resignificando demandas y posicionamientos del campo religioso y político y, al mismo tiempo, precisando los aliados y adversarios en dichos espacios. Veamos brevemente cada uno de esos ejes.

Eje 1. La presentación de un nuevo proyecto de libertad religiosa. Con su propuesta de ley de cultos, la diputada Hotton se apropió de una demanda histórica de las comunidades evangélicas, orientada a la gestión de marco de igualdad para los actores que componen el campo religioso:

Desde el día en el que asumí como diputada de la Nación, me comprometí como cristiana evangélica a tomar la bandera que muchos han estado levantando durante más de veinte años, intentando que nuestras iglesias dejen de ser interpretadas como fundaciones, clubes u ONG para ser consideradas como instituciones religiosas respetadas y reconocidas legalmente (Cynthia Hotton, discurso en la primera reunión de VPMP, Hotel Rochester, 29/11/2008).

El anudamiento entre el proyecto personal y la causa colectiva evidenciaron la pretensión de la diputada de posicionarse como referente del histórico reclamo de su comunidad de fe y, de esta manera, capitalizar su apoyo en tanto su representante. Como condición de posibilidad del proyecto, Hotton subrayó públicamente el acuerdo celebrado previamente con la jerarquía católica:

Este proyecto es el resultado de un estudio de varios años. Antes de lanzarlo a la Cámara, yo me reuní con el cardenal [Jorge Bergoglio] y le dejé 
el proyecto para que lo estudiara. Él me lo devolvió a los dos meses y me dijo que estaba de acuerdo, que no encontraba impedimentos para su promulgación (Cynthia Hotton, discurso en la primera reunión de VPMP, Hotel Rochester, 29/11/2008).

El espíritu de la citada propuesta legislativa se orientaba, por un lado, a mantener intacta la posición diferencial de la Iglesia Católica en el campo religioso ${ }^{6}$. Por el otro, a crear la figura de la personería jurídica religiosa para aquellas confesiones que se inscribieran en el Registro Nacional de Entidades Religiosas (Proyecto de Ley de Libertad Religiosa, 2010, art. 8) y acreditaran presencia efectiva en el territorio argentino, un informe detallado de los principios y doctrinas religiosas y la identificación de autoridades administrativas. El reconocimiento estatal permitía la exención de impuestos fiscales, la inembargabilidad e inejecutabilidad de los templos, lugares de culto y objetos sagrados y el libre acceso de sus ministros a las cárceles, hospitales, asilos y dependencias de las Fuerzas Armadas (Proyecto de Ley de Libertad Religiosa, 2010, art. 9, incisos 2 y 6 y art. 15, incisos 3, 4 y 6). El proyecto de Hotton también excluía de la nominación religiosa el estudio de la parapsicología, la astrofísica, la astrología, las prácticas adivinatorias o mágicas, las prácticas satánicas y a los cultos cuyos oficios religiosos incluyan actos de crueldad sobre animales (Proyecto de Ley de Libertad Religiosa, 2010, art. 6) ${ }^{7}$.

Si se lo compara con los proyectos y anteproyectos antecedentes (Wynarczyk, 2009:237-242, 248-255), la propuesta de Hotton mantuvo la concepción del Estado como árbitro de la cuestión religiosa y la pretensión de extender las prerrogativas católicas a otras confesiones, tal como marcaba el anteproyecto del Consejo Nacional Cristiano Evangélico (CNCE) de 2001 (ibidem:311). Su principal innovación residió en el desplazamiento del catolicismo del lugar de histórico antagonista de los derechos evangélicos y la postulación, en su reemplazo, de otros cultos, como los afroamericanos y las prácticas asociadas a la adivinación y el curanderismo.

Eje 2. La oposición a la despenalización del aborto y al matrimonio entre personas del mismo sexo. Esta agenda se alineó con las críticas que las federaciones Aciera y FeCEP hicieron públicas en los debates sobre Ley de Unión Civil (2003) y de Educación Sexual (2004). Los argumentos coincidentes fueron la postulación de la sacralidad de la vida a partir de la concepción y la indisociabilidad entre los términos "matrimonio" y 
"heterosexualidad". Además de definir como aliadas a las mencionadas federaciones, esta formulación ayudó a definir como antagónicos a su proyecto político a los protagonistas de estas demandas (sectores feministas y del movimiento de la diversidad sexual) y a los actores políticos sensibles a estas reivindicaciones (funcionarios y legisladores).

En esta perspectiva, durante las reuniones preliminares de VPMP en el Hotel Rochester, se enfatizó la intervención de la diputada en el debate en torno al aborto, en el cual Hotton alegó haber frenado un proyecto de las diputadas Juliana Di Tullio y Nora Cesar orientado a ampliar los casos de abortos no punibles (La Nación, 10/11/2008). También se destacó públicamente la oposición de Hotton al proyecto de extensión del beneficio de las obras sociales a parejas convivientes del mismo sexo (Pulso Cristiano 118, 4/9/2008).

Eje 3. El discurso anti-corrupción y por la transparencia en las prácticas políticas. El discurso anticorrupción cuenta con una larga trayectoria en el campo partidario argentino y fue reivindicado por espacios ideológicos antagónicos para trazar una distinción constante entre una "vieja política" y una praxis renovadora. En esta narrativa, gravitan dos lecturas diferenciadas: una enfocada en la cuestión de la ineficacia de las élites políticas para gestionar los bienes públicos y otra, en la denuncia contra la impunidad del poder y la violación de las instituciones democráticas (Mauro, 2011). La apropiación de Hotton de este discurso anticorrupción se acerca a la segunda vertiente, a partir de su crítica al clientelismo. Hotton construyó su propia versión de la antinomia "vieja política-nueva política", criticando las prácticas partidarias "tradicionales" por su distanciamiento con las demandas ciudadanas y ponderando los proyectos religiosos emergentes, estructurados a partir de la lógica del servicio y la construcción de iniciativas en pos del bien común y posicionados en definitiva como agentes renovadores ${ }^{8}$.

Al encontrarse atravesadas por una visión moral, estas propuestas fueron articuladas en la construcción de una frontera política: el clivaje de los valores. La noción de "clivajes", tal como formulado por Lipset y Rockan (1967), alude a las divisiones históricas que atravesaron el campo social en las sociedades occidentales modernas y que se expresan en el campo político, a partir de la mediación de los partidos. Las divisiones sociales "clásicas" se disponen en los siguientes pares binarios: Iglesia-Estado, campo-ciudad, agricultura-industria, centroperiferia, propietarios-trabajadores. En el caso en cuestión, Hotton se 


\section{Marcos Carbonelli}

propuso organizar el campo político bajo un nuevo tipo de clivaje, un clivaje post-ideológico, que distinguió entre "corruptos y los que promueven la cultura de la muerte" de un "nosotros" definido por la defensa de un estilo transparente y honesto de "hacer política" y por una agenda pública asociada a pautas y nociones de bien común extraídos del campo religioso.

En las reuniones preliminares en el Hotel Rochester, también se definió la estrategia de posicionamiento en el campo político:

La idea es formar un grupo que pueda negociar con los partidos, porque ellos están interesados en contar con nuestra fuerza. Nosotros tenemos que tener la capacidad de negociar con el ARI, por ejemplo, y, a partir de eso, seleccionar a cinco de los nuestros, que estén preparados, para que pasen a ser candidatos por ese partido (...) Con la estrategia de participar desde varios partidos tenemos más libertad (Jorge Ducdoc, primera reunión de VPMP, Hotel Rochester, 29/11/2008).

La estrategia de colocar cuadros propios en diversas estructuras partidarias acentuó la intención de diluir las adscripciones ideológicas en pos de identidades de mayor peso, como la pertenencia religiosa. También desvinculó a VPMP del modelo de partido confesional evangélico de los 1990 y lo acercó a un formato de intervención semejante al de la Iglesia Universal del Reino de Dios (IURD) en el contexto político brasileño: una estructura para-partidaria ${ }^{9}$ ¿Cuáles eran los capitales en los que VPMP sustentaba su capacidad de negociación con otras élites políticas? Las siguientes declaraciones de sus referentes arrojan luz al respecto:

De aquí tienen que salir candidatos a intendentes, a concejales, a gobernadores, a diputados nacionales. (...) Tenemos que pensar en las legislativas del 2009. El tiempo nos apremia, pero podemos. Haremos un lanzamiento con todo en marzo y será masivo, multitudinario, como todo lo que hacemos los evangélicos. El acto tiene que salir bien, no puede salir mal. Tenemos que demostrar que somos muchos, para negociar. La política es número y volumen. Vendrán los medios, veremos a qué líderes sociales y religiosos invitamos (Cynthia Hotton, primera reunión de VPMP, Hotel Rochester, 29/11/2008).

A nivel de marketing político, existe un nicho ausente: "los valores". Es un gran negocio, una oportunidad histórica. El mundo lo pide, la Argentina lo pide. Nosotros [los evangélicos], por definición, estamos asociados a los valores. Tenemos que aprovechar eso y empezar a traba- 
jar. Nosotros tenemos agua para dar de beber. Y los evangélicos también tenemos una ventaja comparativa; perdonen si utilizo un lenguaje del marketing, pero es así: para cada cosa que nos convocan somos miles, y súper militantes. No somos una peña política, no damos choripán. Tenemos que irrumpir. No hay pueblos donde no estemos, hacemos un trabajo capilar y esto constituye un capital inapreciable. Para un político, juntar mil doscientas personas es muchísimo, una gran demostración de fuerza. Los tiene que pagar (Jorge Ducdoc, tercera reunión de VPMP, Hotel Rochester, 12/3/2009).

El primer recurso con el que VPMP contaba era el potencial numérico de evangélicos, entendido como un movimiento de masas susceptible de ser movilizado a partir de un liderazgo que articule sus diferencias. Subyace en este planteamiento una visión cuantitativa de la dinámica política, donde lo que importa es exhibir poder de convocatoria para aumentar los márgenes de negociación.

Unido a esto, el segundo capital destacable es el trabajo social de los evangélicos, que se diferenciaría del realizado por los políticos por su carácter genuino ("no somos una peña política", "no damos choripán") y por su "capilaridad", es decir, por su eficacia para alcanzar a quien realmente se encuentra necesitado, por fuera de estructuras prebendarias y mediaciones burocráticas.

En su unidad y permanente superposición, las dimensiones identitarias y estratégicas descritas condensan lo que podemos denominar la apuesta representativa de VPMP: un proyecto orientado a producir vínculos de identificación al interior de un espacio social determinado (en este caso, la comunidad evangélica), de manera tal que dichos lazos se traduzcan en una fuerza electoral o bien en una fuerza de respaldo a un determinado líder, partido, ideología. En tanto el fenómeno de la representación se funda en una dimensión eminentemente performativa (Novaro, 2000), la apuesta representativa condensa un conjunto de acciones, estratégicas y simbólicas, orientadas a que un líder logre (procesualmente) hablar legítimamente en nombre de un colectivo social. Como destacamos en la introducción, consideramos que el trabajo efectuado sobre el vínculo representativo muta en el tiempo, se encuentra en permanente construcción y reflexión, gracias a la variabilidad constitutiva de la dinámica electoral.

La apuesta representativa de VPMP se puso en escena en el lanzamiento de la agrupación llevado a cabo el 31 de marzo de 2009 en la Federa- 
ción de Box. Concurrieron alrededor de mil personas (Noticias Urbanas, 9/4/2009), en su mayoría fieles, pastores y líderes de Iglesias del conurbano y la ciudad de Buenos Aires. Entre las figuras políticas y religiosas presentes que apoyaron el espacio emergente se encontraban Rubén Proietti (presidente de Aciera), el rabino Bergman (una de las figuras de la comunidad judía argentina más populares), Gabriela Micchetti (vicejefa del gobierno porteño) y los diputados por el PRO, Paula Bertol y Federico Pinedo, este último líder de la bancada del PRO en la Cámara de Diputados.

\section{VPMP COMO MONOBLOQUE PARLAMENTARIO: AJUSTES EN LA APUESTA REPRESENTATIVA}

De cara a las elecciones legislativas de 2009, Hotton presionó para que el pastor Christian Grillo (jefe de su campaña electoral en 2007 y por entonces su jefe de despacho) se convirtiera en candidato a la legislatura porteña por el PRO. Esta demanda cobró particular relieve si se tiene en cuenta que la ruptura entre Recrear y CPC a comienzos de 2009 había debilitado la situación de Hotton en la arena partidaria: su bancada nacional era consecuencia de un acuerdo interpartidario que ya no existía.

Sin embargo, la decisión de la cúpula partidaria del PRO fue no otorgarle a Grillo un lugar competitivo en las listas: le concedieron el puesto veintitrés, frente al pedido de Hotton de que figurara entre el cuarto y el octavo lugar (Clarín, 24/04 / 2009). En agosto de 2009, Hotton resolvió abandonar el bloque del PRO en la Cámara de Diputados y transformar a VPMP en un monobloque parlamentario.

En una reunión extraordinaria de VPMP el 6 de agosto de 2009, la diputada comunicó a los miembros de su espacio los motivos de su decisión. A las desavenencias por el caso Grillo, agregó el siguiente episodio:

Para el acto de lanzamiento de VPMP habíamos hecho el afiche para la convocatoria de Valores, usando la misma gráfica que lo que fue el acto de Ale Gómez, contra el aborto, en el Parque de la Costa. Y ese afiche, tenía una leyenda muy chiquita, abajo, que decía "no a la despenalización del aborto".

Bueno, en el PRO me dijeron que Gabriela [Michetti] sólo podría ir al lanzamiento de Valores si quitábamos esa leyenda, porque no era tema de campaña y complicaba las cosas. Lo aceptamos, pero también me 
molestó mucho (Cynthia Hotton, discurso en la reunión extraordinaria de VPMP, 6/8/2009).

Los condicionamientos impuestos a la presencia pública de Gabriela Michetti y el lugar poco competitivo concedido al pastor Grillo visibilizaron la distancia entre las intenciones de Hotton de posicionar el clivaje de los valores como agenda prioritaria y a la movilización evangélica como recurso. También pusieron de manifiesto las consideraciones estratégicas de dirigentes políticos que prefirieron no pronunciarse sobre temas controversiales en período de campaña y no considerar a los evangélicos como una fuerza política en sentido pleno.

En su nueva etapa como monobloque, Hotton procuró reposicionar a VPMP intentando convertirse en un liderazgo atrayente para la opinión pública, a partir de una continua escenificación de su pertenencia religiosa y de su agenda centrada en el discurso de valores. Así intentó vincularse con figuras relevantes del ambiente político, y el vicepresidente Julio Cobos fue la personalidad política con la que mantuvo mayor contacto. El vínculo entre ambos se inició con la visita de Luis Palau a Argentina en marzo de 2008 (cuando el predicador fue recibido por el vicepresidente en su despacho en la Casa Rosada) y se afianzó con los encuentros de oración que Hotton y Cobos mantuvieron en el contexto del conflicto entre las entidades agrarias y el gobierno y en las reuniones preliminares de VPMP. En declaraciones públicas, Cynthia Hotton lo respaldó frente a las críticas del oficialismo por su voto "no positivo", alegando que el vicepresidente era en verdad "el garante del Gobierno" (Perfil, 14/10/2008), y que resultaba "una figura política distinta a la de Chacho y Scioli" (Tiempo Argentino, 25/11/2008), los vicepresidentes anteriormente electos.

La intención era favorecerse tanto de la imagen positiva de Cobos en los sondeos de opinión como de su impacto mediático ${ }^{10}$. También estos posicionamientos reafirmaron la pertenencia de Hotton al arco opositor en el campo partidario nacional: evitó mostrarse con dirigentes del kirchnerismo una vez consumada su salida del espacio bajo el cual fue electa y sus votaciones durante su mandato se mantuvieron bajo un signo antagonista con respecto a las propuestas del oficialismo.

Esta estrategia de acumular capital político a partir de la exhibición mediática se plasmó particularmente en la intervención de Hotton en tres controversias legislativas en 2010: el debate sobre el matrimonio entre personas del mismo sexo con potestad para la adopción; la pre- 
sentación del proyecto de ley de cultos; y su denuncia de corrupción en torno a la presentación de la ley de presupuesto.

\section{Debate sobre el Matrimonio entre Personas del mismo Sexo: Reconfiguración de la Apuesta Representativa}

El debate sobre el matrimonio entre personas del mismo sexo alcanzó su epicentro en el primer semestre de 2010. En dicho período, ingresaron a las comisiones de Familia, Mujer, Niñez y Adolescencia, y de Legislación General de la Cámara de Diputados dos proyectos, impulsados por las diputadas Vilma Ibarra y Silvia Ausburger, respectivamente. Estas iniciativas se unificaron el 15 de abril para impulsar el derecho al matrimonio para parejas homosexuales, que incluía la potestad de la adopción de menores.

Cynthia Hotton fue una de las principales detractoras públicas de esta iniciativa. Durante su tratamiento en las comisiones, afirmó que el "matrimonio es entre un hombre y una mujer porque así lo dispuso Dios" (Cynthia Hotton, discurso en el debate de la Comisión de Familia, Mujer, Niñez y Adolescencia, 15/4/2010), aunque también ofreció argumentos extraídos del campo jurídico y científico, utilizados para debilitar las acciones de los adversarios, los promotores del proyecto. Citó ejemplos de legislación comparada ("el 96,5 \% de los países no tienen matrimonio para homosexuales". Cynthia Hotton, publicado en La Nación, 20 /4/2010) e informes psicológicos de renombre internacional "que indican que las parejas homosexuales son más propensas a separarse que las heterosexuales, y esto resulta perjudicial para la salud emocional de los niños" (Cynthia Hotton, discurso en el debate de la Comisión de Familia, Mujer, Niñez y Adolescencia, 15/4/2010).

La apelación a argumentos seculares, pero también a fundamentos divinos, puso en escena, por un lado, la preocupación de Hotton por ajustar sus acciones a la gramática del debate público-legislativo, apartándose de posiciones y argumentos particulares, y elevando sus justificaciones al plano del interés común (Boltanski, 1990). Por el otro, la exhibición de la adscripción religiosa resultó el eje de nuevas alianzas y acciones, como la organización de una movilización pública contra el matrimonio homosexual:

Igualar hoy el matrimonio para personas del mismo sexo representaría producir una falta de sintonía entre la legislación y la manera en que vive y piensa la mayor parte de los ciudadanos, no solo de la Argentina, 
sino también del mundo (...) Junto a diferentes organizaciones y ciudadanos autoconvocados, nos reuniremos hoy, a las 19, frente al Congreso de la Nación para expresarnos. Queremos que cada niño adoptado tenga un papá y una mamá. Será un acto en favor de los valores que defendemos para nuestro país. Vamos a ser miles y miles los argentinos que digamos "no" al matrimonio homosexual con adopción (Cynthia Hotton, publicado en La Nación, 20/4/2010).

Hotton intentó posicionarse como portavoz de una demanda y de un ideario de valores que, según su discurso, resultaba compartido no sólo por liderazgos religiosos sino también por una mayoría ciudadana ${ }^{11}$. Las citadas evocaciones a "los miles de argentinos que dicen no" y al desacuerdo de "la mayoría de los ciudadanos" dan cuenta de la constitución retórica de un colectivo conformado por los ciudadanos que comparten valores estrictamente definidos por un ideario moral con bases religiosas. En este sentido, la figura de una mayoría moral en la Argentina fue construida inicialmente bajo los atributos del cristianismo, pero luego desarrolló un marco de referencia más amplio, incluyendo planteos doctrinarios comunes a sectores conservadores de las principales religiones monoteístas, para interpelar no sólo a fieles evangélicos, sino también a creyentes afiliados a vertientes conservadoras de otras religiones y también a no creyentes. Esta actitud reveló el ajuste definitivo en la apuesta representativa de VPMP: frente a la problemática escenificación de la fuerza evangélica, la diputada evangélica acentuó aquellos diacríticos que hipotéticamente funcionan como comunes denominadores de la cultura cristiana, para constituirse en referente de un nuevo espacio en el que las marcas de pertenencia religiosa rubrican la importancia de un núcleo de valores compartidos.

Bajo el lema "Queremos que cada niño tenga un papá y una mamá", la concentración opositora tuvo lugar el 20 de abril de 2010, frente al Congreso Nacional. Si bien el evento mantuvo un marcado acento evangélico, Hotton se ocupó de invitar especialmente a las senadoras nacionales Liliana Negre de Alonso y Norah Castaldo, y al diputado Julio Ledesma, quiénes remarcaron públicamente su adscripción religiosa al catolicismo y su apoyo a futuras acciones opositoras.

En el plano de las alianzas, el apoyo de diferentes figuras del espacio religioso a la iniciativa de Hotton se cristalizó en acciones conjuntas que a posteriori desarrollaron actores católicos, evangélicos, judíos y musulmanes (La Nación, 1/7/2010), tanto en dos nuevas movilizacio- 
nes contra el matrimonio entre personas del mismo sexo como en los medios masivos de comunicación. Durante los meses de abril, mayo y junio de 2010, la figura de Cynthia Hotton fue posicionándose como la cara visible de un frente interconfesional que se enfrentó a los legisladores y militantes que luchaban por la sanción de la ley de matrimonio homosexual.

Sobre el final del debate legislativo, la diputada evangélica junto con la senadora Liliana Negre de Alonso presentaron un petitorio con firmas recolectadas en audiencias públicas, en templos católicos y evangélicos y en colegios confesionales de diferentes regiones del país, en el que solicitaban la suspensión del debate legislativo y el llamado a una consulta popular (La Nación, 1/7/2010) ${ }^{12}$.

Pese al fracaso de esta iniciativa y a la definitiva sanción de la ley en cuestión, la alianza interreligiosa se consolidó y se reprodujo en el debate sobre la despenalización del aborto, controversia que tras la sanción del matrimonio homosexual volvió a instalarse en la arena pública. En agosto de 2010, Hotton y la senadora Negre de Alonso organizaron la red Unidos por la Vida, que nucleó a organizaciones católicas y evangélicas en contra de la despenalización del aborto, entre las que se destacaron la asociación Argentinos por los Chicos (donde participó el vicepresidente de Aciera, Gastón Bruno) y la organización Impacto Social y Político, perteneciente a FeCEP (Tiempo Argentino, 6/10/2010). Dicha red llevó adelante la organización de charlas informativas sobre el tratamiento legislativo de esta causa, campañas gráficas de concientización y la presentación mediática de sus principales referentes.

La intervención de Hotton también propició una fractura en el espacio evangélico. Durante el debate en torno al matrimonio entre personas del mismo sexo, iglesias de tradición protestante se diferenciaron de los pronunciamientos públicos de Aciera y FeCEP y de la diputada Hotton, criticando tanto la interpretación anacrónica y conservadora de textos bíblicos como las propuestas políticas justificadas en la gravitación de una mayoría y / o una moral religiosas (Jones y Carbonelli, $2012)^{13}$. Estas críticas asumieron una vital importancia porque desmantelaron uno de los argumentos nodales de la oposición religiosa al matrimonio homosexual, pero también porque visibilizaron la disputa interna por la nominación del "nosotros evangélico" y generaron una lógica centrífuga que continuó en el tratamiento de la ley de libertad religiosa. 


\section{Ley de Cultos: Resignificación de una Demanda Histórica}

El proyecto impulsado por la diputada Hotton ingresó a la comisión de Relaciones Exteriores y Culto en agosto de 2009. Sin embargo, durante ese año, su tratamiento resultó afectado por una controversia pública en torno a su artículo 31: la figura del "delito contra la libertad religiosa y de conciencia", que preveía una modificación del Código Penal para adjudicar penas de seis meses a dos años de prisión "para quien agrediere de hecho o de palabra a un ministro de una confesión religiosa reconocida en ocasión del ejercicio de actos propios de su ministerio o por el hecho de serlo" (Proyecto de Ley de Libertad Religiosa, 2010, art.31). Tras estos obstáculos, el 29 de abril de 2010, el proyecto volvió a ser presentado en la mencionada comisión y, para dicho acto, Cynthia Hotton organizó una reunión pública, donde se mostró rodeada de líderes de diferentes confesiones (rabinos, imanes y obispos de la iglesia ortodoxa, entre otros), a los fines de exhibir un consenso interreligioso en torno a su iniciativa.

Cuando, en el mes de agosto de 2010, el proyecto Hotton se prestaba a ser tratado por las comisiones de Legislación General y Comunicaciones e Informática, nuevos cuestionamientos impidieron su debate final en el Parlamento. Las críticas más intensas provinieron de diferentes sectores evangélicos: en un documento publicado el 29 de agosto de 2010, la FAIE remarcó que el proyecto de Hotton, al mantener la premisa histórica de la intangibilidad de los privilegios de la Iglesia Católica, desconocía el vector esencial de la demanda evangélica: la igualdad ${ }^{14}$.

Para dicha federación, en la medida en que el proyecto concedía al Poder Ejecutivo "la facultad de controlar a las comunidades religiosas diferentes a la oficialmente establecida" (FAIE, 2010), sus pretensiones contradecían el derecho de libre expresión y ejercicio de la libertad religiosa en Argentina, debidamente respaldados por el artículo catorce de la Constitución Nacional y los acuerdos internacionales suscritos. Observando como premisa que "el debate no puede tener como punto de partida la vigencia del actual Fichero de Cultos o algo similar" (idem), la federación evangélica cerró su comunicado alegando que las comunidades que la integran "no buscan ni desean privilegio alguno". También alzó su voz opositora el pastor pentecostal Guillermo Prein de la Iglesia Centro Cristiano Nueva Vida (CCNV), una de las congregaciones más numerosas de la Argentina (integrada aproximadamente por cuarenta mil miembros). Prein cuestionó los privilegios y atribu- 
ciones que el proyecto concedía a las entidades de segundo y tercer grado (federaciones y/o confederaciones), por encima de las comunidades e iglesias locales, en particular la capacidad para celebrar convenios con el Estado nacional y los estados provinciales, facultad de funcionar como órganos de control e intervención de las entidades de primer grado. Estas pretensiones fueron interpretadas por el pastor Prein como "un nuevo escalón de desigualdad al ya existente con el culto católico apostólico romano" (Prein, 2010).

La falta de consenso al interior de la comunidad evangélica y el nivel de conflictividad pública alcanzado inclusive motivaron a la federación Aciera a abandonar su apoyo original al proyecto y recomendar la suspensión de su tratamiento, para revisar con exhaustividad sus puntos más controvertidos. Finalmente, líderes umbandas, los sectores más perjudicados por el proyecto Hotton, presentaron una queja formal ante la Secretaría de Cultos.

En definitiva, las tensiones desencadenadas en torno al matrimonio homosexual influyeron en el desarrollo del proyecto de libertad religiosa, porque lejos de aplacarse por el tratamiento de una causa común, se volvieron a activar sobre los ejes de la relación con el Estado y la representación colectiva. El devenir de esta iniciativa impactó en la trayectoria política de Cynthia Hotton y de su espacio porque acentuó el desplazamiento de su apuesta representativa hacia la interpelación a un público pluriconfesional, articulado en torno al clivaje de los valores.

\section{Denuncia de Corrupción en la Cámara de Diputados}

El 13 de noviembre de 2010, durante el tratamiento de la ley de presupuesto, Hotton denunció ante sus pares de cámara haber recibido un ofrecimiento de soborno, para que abandonara su oposición al proyecto oficialista. En un primer momento, la diputada declinó ofrecer el nombre del autor / a del ofrecimiento, aduciendo que le interesaba más el problema de la corrupción como práctica estructural del parlamento que dar nombres propios. Sin embargo, Cynthia Hotton acusó finalmente a la diputada del FPV, Patricia Fadel, argumentado que la legisladora oficialista y vicepresidenta de la Cámara de Diputados le habría ofrecido dinero y el apoyo del bloque kirchnerista para algunos de sus proyectos a cambio de su voto favorable a la ley de presupuesto o su ausencia en la votación final. La diputada Fadel se defendió, contradiciendo las afirmaciones de Hotton al sostener que había sido en verdad 
la titular del monobloque VPMP quien la había contactado primero, solicitándole apoyo para una declaración a favor de la vida. Fadel añadió que, además de injuriar su posición como diputada, Hotton ponía en evidencia su desconocimiento de una práctica parlamentaria habitual y legítima como la búsqueda de apoyos y la negociación de acuerdos entre legisladores de diferentes bloques (Página 12, 19/11/2010).

Por la centralidad del proyecto para la gestión económica del país y por la gravedad de la acusación formulada, la denuncia de Hotton recibió una amplia cobertura mediática. Esto activó una segunda oleada de denuncias por parte de algunos sectores de la oposición, quienes también alegaron haber sido presionados por el oficialismo (Clarín, $17 / 11 / 2010)^{15}$. De forma paralela, legisladores del kirchnerismo y periodistas de diversos diarios cuestionaron el carácter endeble de las pruebas de soborno y las contradicciones de la diputada con respecto al llamado de la diputada Fadel.

Luego de varias semanas, la controversia perdió peso dentro de la agenda mediática, conjuntamente con la finalización del debate parlamentario. El gobierno no obtuvo la cantidad de votos requerido y resolvió aplicar el presupuesto correspondiente al año precedente (2009). Por falta de pruebas, la acusación contra la diputada Fadel no hizo mella en su trayectoria política.

En su balance, Hotton destacó la repercusión mediática de su denuncia como un fenómeno que le permitió ampliar las bases de sustentación de la agrupación política:

Cuando fue el tema del matrimonio homosexual, todo ese debate, ahí fue cuando me hice más conocida y se acercaron muchísimos católicos. Muchísimos (...) Y la mayoría de los que están hoy en VPMP son gente que conocí en estos años. Y el último ingreso muy fuerte fue con mi denuncia de corrupción, porque mucha gente ahí me vio creíble. Y me vio creíble justamente porque fue en temas que no hacen a lo religioso, o sea... Porque todo el tema del matrimonio homosexual, si bien los argumentos que planteamos no eran religiosos, todos aquellos que profesan una religión les interesaba donde estaba quien profesa la defensa de la familia. Ahí me vieron.

Pero después me vieron en otro rol, donde me jugué. Y qué sé yo, lo que te dicen es que ahí vieron de parte mía mucho liderazgo, como decir, "me la jugué sola y lo hice igual" y mucha transparencia. Desde lo testimonial, digamos, pude recibir mucho más apoyo, porque como yo tuve 
mucha exposición en los medios, en realidad llegué al pueblo, es decir, a la comunidad evangélica, a la gente, no a través de los pastores (Cynthia Hotton, entrevista personal, 10/1/2012).

La cita precedente ratifica la ponderación de los medios como agentes medulares en la difusión del clivaje de los valores y, fundamentalmente, en la popularización de su figura. La evaluación de Hotton acerca del impacto de las controversias públicas reafirmó su intención de acentuar el horizonte pluriconfesional de la apuesta representativa de VPMP. Esta decisión determinó un cambio en la fisonomía de la agrupación, que se afirmó con el ingreso de católicos a sus filas: VPMP mantuvo su sesgo post-ideológico, pero abandonó su anclaje explícito en demandas evangélicas para convertirse definitivamente en un espacio pluriconfesional con pretensiones políticas. La articulación de estos elementos desencadenó la constitución de VPMP como partido político y la construcción de su perfil en las elecciones generales del segundo semestre de 2011.

\section{LAS ELECCIONES DE 2011: VPMP COMO UN PARTIDO DE IDENTIDAD "CRISTIANA"}

Durante los meses de enero y febrero de 2011, Cynthia Hotton decidió que no intentaría renovar su banca en la Cámara de Diputados de la Nación. El nuevo escenario de competencia sería la legislatura de la ciudad de Buenos Aires, con la diputada evangélica como cabeza de lista. Hotton justificó esta decisión por la afinidad establecida entre la ciudad de Buenos Aires, entendida como área de debate, los ejes identitarios de VPMP y la gravitación pública que había adquirido su figura durante 2010 .

Sin embargo, un factor que recortó proyecciones más ambiciosas de VPMP fue el declive de figuras políticas en las que, tras su ruptura con el PRO, Hotton había depositado expectativas para potenciar su espacio político. Luego de un período de extensa popularidad mediática con la denominada "crisis del campo", la trayectoria del vicepresidente de la nación, Julio Cobos, perdió gravitación en el escenario partidario, debido a la recuperación de la agenda política por parte del kirchnerismo ${ }^{16}$ y a las tensiones acontecidas en el interior del propio radicalismo. De cara a las elecciones generales de 2011, el vicepresidente de la Nación no se había convertido en la figura articuladora de la oposición al kirchnerismo ni se mostraba con una proyección favora- 
ble en los comicios. Por su parte, también la trayectoria política de Gabriela Micchetti había sufrido un notorio desgaste al interior del PRO, desplazada por sectores del propio partido más afines a la proyección política del jefe de gabinete porteño, Horacio Rodríguez Larreta.

Ante este panorama, la ciudad de Buenos Aires ofrecía un territorio más accesible, tanto en lo que refiere a los criterios legales para formar el partido, como a la presencia de un electorado caracterizado por la autonomía y por su sensibilidad a los clivajes políticos escenificados en los medios masivos de comunicación (Mauro, 2011). Hotton apostó a la construcción de un relato que remarcaba un estado de "crisis de representatividad", por la ausencia de una agenda de valores en la gestión pública y en la plataforma política del resto de los candidatos:

Nos interesan los temas que los otros candidatos no quieren tocar: la familia, los valores, la vida (...) Creemos que la mayoría de los candidatos, sino todos, están descuidando un sector de la población que quiere defender estos valores (Cynthia Hotton, publicado en La Nación, 7/7/2011).

Al momento de definir su perfil de cara al período eleccionario, la permanente asociación mediática de su figura con el cristianismo apuntaló la estrategia de diferenciación de la candidata, al mismo tiempo que diseñó un perfil de votantes definidos:

Lo del cristianismo es un sello distintivo. Yo me di cuenta [es] que ya la gente me tiene asociada con que soy cristiana.

A todos les queda muy en claro que recibo mucho apoyo de sectores judíos. Y bueno, de católicos, ni te cuento, así que, digamos, no tengo ningún problema, pero sí que cuando digo cristiano, digo cristiano amplio...no es "evangélico" solamente (...) Lo que nosotros queremos aportar desde VPMP es un espacio político, con una identidad propia muy definida, muy clara, donde hoy estoy yo, mañana estará otro, pero la plataforma es esta (...) Así como hay, qué sé yo, hay un Partido Obrero, que la gente que los vota ya sabe por qué los vota, es un núcleo, "el Partido Obrero defiende tal y cual cosa"; y hay años que les va muy bien y hay años que no, pero digamos que es un partido que es fuerte en lo que defiende, y cuando salen esos temas, tienen algo para decir. Bueno, nosotros queremos hacer, ser lo mismo, tener una identidad propia, muy definida, de defensa de valores, tener representación en el Congreso, para que cuando salgan estos temas, decir: “¿dónde está el nú- 
cleo duro de la defensa de la vida?", bueno, en VPMP (Cynthia Hotton, entrevista personal, 10/1/2012).

En la propaganda gráfica, esta marca distintiva se hizo explícita en el slogan "Votá Valores Cristianos", en el detalle de los principios de la agrupación y en la expresa identificación de los candidatos de la lista de VPMP con una militancia en el campo religioso ${ }^{17}$.

La propuesta electoral de VPMP en la ciudad de Buenos Aires se concentró en dos puntos primordiales: a) la reivindicación del liderazgo de Hotton, a partir de la mediatización de su figura en los debates en torno al matrimonio homosexual, a la despenalización del aborto, y en la denuncia de corrupción formulada al interior de la cámara de diputados, y b) la traducción de los valores como ejes identitarios de una comunidad cristiana, cuyo intereses se pretendía representar en la arena partidaria.

Todas las acciones de campaña estuvieron orientadas a reforzar los marcadores identitarios del partido. Templos evangélicos, pero también parroquias católicas de la ciudad de Buenos Aires constituyeron escenarios de difusión de las propuestas de VPMP y de los principales candidatos de la lista. En cada uno de los debates televisivos en los que participó, Hotton acentuó su oposición al aborto, alertó acerca del ingreso masivo de candidatos que intervinieron positivamente en el debate por el matrimonio homosexual y denunció la falta de transparencia generalizada en el ambiente de la política. También remarcó, mediante una lista de correos internos, su apoyo explícito a una serie de candidatos, en el Conurbano Bonaerense, pero también en el interior del país, que se habían destacado por su labor orientada a favor de la "defensa de la vida".

En el marco de un escenario electoral porteño polarizado por la competencia de dos figuras excluyentes - Mauricio Macri y Daniel Filmus -, VPMP obtuvo en las elecciones del 10 julio de 2011 un total 18.335 votos que no alcanzaron para obtener lugares en la legislatura porteña.

En una carta de agradecimiento dirigida a los militantes de VPMP, Hotton reconoció que la tardía conformación del partido, la ausencia de un número suficiente de fiscales propios y de candidatos en todas las comunas de la ciudad y la compleja estrategia del corte de boleta constituyeron obstáculos que terminaron por delinear una performance electoral inferior a las expectativas planteadas (Cynthia Hotton, 
"Carta a los militantes de VPMP", 12/7/2011). Sin embargo, en el mismo comunicado manifestó sus intenciones de seguir involucrada en el mundo de la política, a partir de la continuidad del espacio:

Lo bueno es que no sólo reconocemos nuestros errores, sino que también aprendemos. Este nuevo tiempo será para meditar y reflexionar en las nuevas estrategias. Seguimos convencidos de que tenemos que participar porque la política necesita valores, gente comprometida con una causa noble, como la nuestra. Esto es un principio de algo que recién comienza. El partido es un instrumento, Valores Para mi País llegó para quedarse (idem).

Las "nuevas estrategias" remitían a una reconfiguración global del proyecto político de VPMP, a partir de su futura inclusión en un frente de partidos, denominado "Unión de Partidos Provinciales". Según la dirigente, la coincidencia en el perfil de estas formaciones le iba a permitir a VPMP usar esa plataforma para continuar su expansión en los años siguientes, sin duplicar esfuerzos.

Los contactos construidos con sectores católicos durante la oposición conjunta del matrimonio homosexual le habilitaron un cargo en la Universidad Austral, como directora ejecutiva de la Diplomatura en Liderazgo Ejecutivo. Asimismo, Hotton obtuvo un distinción por parte de la organización internacional Enfoque a la Familia como "Defensora de la Vida en Latinoamérica", y esta mención le valió la organización de un ciclo de conferencias propio, donde actualmente asesora a diputados cristianos latinoamericanos en debates como aborto, unión de parejas de mismo sexo, fertilización asistida y eutanasia. En definitiva, Hotton prolongó su trayectoria política, a partir de su conversión en embajadora "global" de los valores cristianos en la arena partidaria.

\section{CONCLUSIONES}

Bajo la oferta política del clivaje de los valores, Cynthia Hotton apostó por constituirse en la referente del espacio evangélico. En sus primeros pasos, su agrupación se alejó del formato de partido confesional y pretendió exhibir y negociar en el mundo partidario la hipotética adhesión de la fuerza electoral evangélica, bien como las ventajas de un discurso y una praxis distante del clientelismo y la corrupción. En el período 2009-2011, la intervención de la líder en debates parlamentarios como el matrimonio para personas del mismo sexo y la ley de presupuesto, sumada a reveses sufridos en negociaciones con liderazgos 
religiosos y políticos, activó la radicalización del clivaje de los valores, y la ampliación del marco de interpelación de VPMP hacia otros espacios religiosos. Es en este momento cuando se abre a una apuesta representativa compleja y con un horizonte pluriconfesional. Estas intervenciones también plasmaron la construcción de un liderazgo mediático ponderado como un nuevo método de acumulación de capital político.

Si se lo compara con las experiencias evangélicas precedentes, VPMP se distingue por la introducción de elementos estratégicos e identitarios novedosos. En primer lugar, el liderazgo mediático de Hotton se convirtió en el eje de articulación de todo el movimiento y su popularidad derivó en una estrategia de acumulación de poder. En ninguna de las experiencias evangélicas previas encontramos un liderazgo tan nítido como el de la diputada evangélica (Cfr. Wynarczyk, 2010). En segundo, la idea de un posicionamiento multipartidario se alejó del formato de partido confesional e incluso desarticuló la histórica afinidad entre los movimientos políticos evangélicos y el peronismo, ubicando, decididamente, a VPMP en un sector del espectro partidario argentino alternativo. Finalmente, su rasgo más innovador fue su propuesta identitaria. A partir de una agenda definida en torno a un clivaje ético, el partido formuló una interpelación sin precedentes, que incluyó no sólo a la comunidad evangélica, sino también a audiencias pluriconfesionales.

La derrota electoral de VPMP en los comicios generales en Buenos Aires en 2011 no representó el final de la carrera política de Hotton, pero evidenció las limitaciones de su apuesta representativa. Su diagnóstico acerca de la "crisis de la política" y de disolución de identidades y estructuras partidarias resultó desfasado frente a un proceso que se caracterizó precisamente por la repartidización de las identidades sociales. A partir de 2003, y con el kirchnerismo como factor dinamizador, la militancia política y el diseño de la agenda pública por parte del Gobierno se posicionaron como los símbolos de una nueva etapa. Como señala Mauro (2011), la distinción "corrupción-transparencia" o "clase política- ciudadanía" mostró signos de agotamiento en un contexto en el que liderazgos y debates específicamente partidarios recuperaron protagonismo.

Por otro lado, la postulación de la convocatoria religiosa como recurso de negociación política, lejos de asegurar el lugar de VPMP en estructuras partidarias, propició su aislamiento. Esta descapitalización res- 
pondió a una sobreestimación de las potencialidades del espacio evangélico, entendido como movimiento de masas, y de su cotización en la percepción de la clase política. También se reveló insuficiente la estrategia de acumular poder político mediatizando la figura de Cynthia Hotton. Los liderazgos mediáticos se caracterizan por la amplitud y la rápida difusión de una imagen política, pero también por la volatilidad e inestabilidad de las adhesiones que generan, y que obligan a considerar territorios de anclaje alternativos (Scherlis, 2009). La performance política de la diputada evangélica también se erosionó como producto de su distanciamiento con reglas implícitas del campo, como la disciplina partidaria y la búsqueda de consensos en el espacio parlamentario.

Un dato insoslayable de la trayectoria inconclusa de VPMP es que no sólo no consiguió generar vínculos estables con la clase política y con la ciudadanía, en su variante de audiencia religiosa. También fracasó en el intento de solidificar alianzas con los propios líderes de su espacio religioso de procedencia. Como analizamos en apartados precedentes, las iniciativas de la diputada fueron motivo de profundas críticas por parte de federaciones y líderes evangélicos, y estas actitudes también minaron su proyección política.

Finalmente, ¿qué implicancias reviste este estudio de caso para los análisis de religión y política en Argentina? En primer lugar y siguiendo el planteo del párrafo precedente, las tensiones suscitadas por las propuestas de VPMP en el espacio evangélico pusieron en escena no sólo diferencias teológicas y doctrinales, sino también la disputa que se activa en su interior en torno a la cuestión representativa. Este es un rasgo que ha sido subrayado por literatura reciente sobre proyecciones políticas evangélicas (Algranti, 2010; Jones y Carbonelli, 2012) y que requiere ser profundizado, en la medida en que se anticipa como el rasgo predominante de la dinámica del mencionado espacio religioso en la actualidad.

En segundo término, si se pone en línea los resultados alcanzados por VPMP con el de los partidos confesionales de la década de 1990, pero también con las breves experiencias católicas de principios de siglo XX (Di Stefano y Zanatta, 2000) y con los consejos recientes difundidos por jerarquías religiosas en tiempo electorales, se observa un denominador común: el fracaso de instituciones o liderazgos religiosos en su propósito de orientar la conductas políticas de fieles y ciudadanos. En 
el caso de VPMP, la interpelación directa a identidades religiosas adquirió una cristalización efímera en las movilizaciones en el espacio público, pero no alcanzó una codificación efectiva en el escenario electoral. La densidad de las identidades partidarias en Argentina y la complejidad que asume el voto como acción individual (a partir de la multiplicidad de intereses y de afiliaciones que en él se anudan) también dieron cuenta de la esterilidad de una oferta ceñida a controversias éticas puntuales, como la oposición al matrimonio entre personas del mismo sexo o a la despenalización del aborto. En lo que se refiere a la dinámica electoral, la decisión de fieles y ciudadanos se presenta irreductible a las influencias religiosas. Sin negar los intercambios y transferencias de legitimidades que históricamente se han celebrado entre espacios políticos y religiosos en Argentina, es posible aseverar que los mismos no son ni permanentes ni omnipresentes, sino que se brindan en circunstancias y espacios específicos. En virtud de esta observación, se torna imprescindible una perspectiva metodológica que identifique niveles diferenciados de contacto entre actores y estructuras políticas y religiosas, y establezca en cada caso la probabilidad de articulación de sus lógicas.

(Recebido para publicação em janeiro de 2014) (Aprovado para publicação em novembro de 2014) 


\section{NOTAS}

1. Comenzamos nuestro análisis en la década del 1990, porque en los 1980 no se registraron experiencias partidarias evangélicas. Las primeras iniciativas políticas evangélicas fueron la Asociación Alianza Evangélica Argentina (1981) y, posteriormente, Civismo en Acción (1982-1983), grupos conformados por abogados y empresarios de congregaciones bautistas y de hermanos libres que procuraron reflexionar sobre y motivar la participación de sus hermanos en la fe en las estructuras partidarias (Wynarczyk, 2010:27). Estas sociedades de reflexión, debate y estudio sobre la praxis política no derivaron directamente en una vía partidaria, aunque algunos de sus miembros ingresaron a título individual a las filas del Partido Demócrata Progresista y otros integraron más tarde el MCI.

2. En las elecciones de 1993, el MCI consiguió 44.540 votos en la provincia de Buenos Aires (0,7\% del total) y 12.854 en Córdoba (Wynarczyk, 2010:106-107). En las constituyentes de 1994, el MCI duplicó su cantidad de votos en Buenos Aires (85.182), pero esta cifra no le bastó para colocar ningún candidato (ibidem:114). Finalmente, en los comicios de 1995, el MCI obtuvo 8.535 votos, que representaban el 0,14\% del total de sufragios, mientras que en Córdoba el MRI se alzó con 5.403 votos (el 0,36\% de los votos) y tampoco accedió a ningún cargo (ibidem:121).

3. Pablo Tschirsch y Hugo Acuña también fueron evangélicos que alcanzaron cargos públicos importantes en el mundo partidario en el nuevo milenio. El primero se desempeñó como ministro de Educación y luego como vicegobernador de la provincia de Misiones durante el período 1999-2007 y a posteriori fue candidato a gobernador y a diputado nacional por dicha provincia en las elecciones de 2007 y 2011, respectivamente. El segundo se desempeñó como diputado nacional entre 2007-2011. A diferencia de Hotton, en sus trayectorias partidarias la identificación religiosa jugó un rol sensiblemente menor y en ningún momento intentaron estrategias políticas que implicaran interpelar a la comunidad evangélica y pretender su representación.

4. Dicha federación nuclea en la actualidad a la mayoría de las iglesias y organizaciones evangélicas y pentecostales en Argentina, entre las que se cuentan las congregaciones de los Hermanos Libres, denominación de origen de la familia Hotton.

5. Tanto Recrear como CPC son formaciones políticas derivadas del proceso de descongelamiento partidario (Mauro, 2011) registrado en el sistema político argentino tras la crisis de 2001. El primero fue uno los desprendimientos de la UCR luego de la caída del gobierno aliancista de Fernando de la Rúa, mientras que la fundación de CPC en 2003 comprendió el armado de Mauricio Macri para proyectarse electoralmente en la ciudad de Buenos Aires, tras su gestión al frente del club de fútbol Boca Juniors. En 2005 ambas fuerzas formaron una coalición de centro-derecha denominada Proyecto Republicano (PRO) para posicionarse como principal fuerza opositora al kirchnerismo. En 2007 reeditaron la alianza, de cara a los comicios generales, aunque múltiples desavenencias y competencias internas provocaron que el pacto sólo se circunscribiera al ámbito electoral de la ciudad de Buenos Aires, donde combinó el armado de una lista en común.

6. El punto nodal del acuerdo era el inciso 2 del artículo $7 \mathrm{del}$ proyecto, donde se mencionaba que "La Iglesia Católica Apostólica Romana mantiene el reconocimiento de su personalidad jurídica pública con los alcances previstos en la Constitución Nacional 


\section{Marcos Carbonelli}

y en las leyes reglamentarias. Sus relaciones con el Estado nacional se rigen por los acuerdos firmados entre éste y la Santa Sede".

7. Según los lineamientos del proyecto, la observancia de estos criterios de exclusividad recaería en el mencionado Registro Nacional de Entidades Religiosas y en el Consejo Asesor de Libertad Religiosa (CALIR) compuesto por miembros de comunidades religiosas de reconocida trayectoria en el país (Proyecto de Ley de Libertad Religiosa, 2010, art. 23).

8. La crítica hacia la clase política en torno al eje "honestidad-corrupción" también observa antecedentes en el campo religioso, fundamentalmente en la década del 1990. Durante el primer gobierno menemista, diversos obispos cuestionaron el uso privado de fondos públicos por parte de funcionarios y las condiciones de extrema pobreza que se observaba en varias provincias, producto de la aplicación de políticas de ajuste (Dri, 1997; Esquivel, 2004). En el caso del campo evangélico, el discurso anticorrupción fue una de las marcas distintivas de las iniciativas de armado de partidos confesionales (Wynarczyk, 2010).

9. Como han indicado varios estudios de la academia brasileña (Oro, 2003; Dos Santos y Schweig, 2004), dicha denominación se comporta en el contexto político-religioso brasilero como una entidad formalmente exógena al sistema partidario, pero que merced a su poder de movilización y a su sofisticada estructura de selección, formación y acompañamiento de sus candidatos, consigue negociar su inclusión en diversas listas partidarias en cada período electoral.

10. Tras su pronunciamiento negativo en la votación sobre la reglamentación de las retenciones a las exportaciones agropecuarias en el Senado nacional, la figura del vicepresidente Julio Cobos alcanzó preponderancia en los sondeos de opinión y en las encuestas sobre imagen positiva. Esta decisión selló su distanciamiento definitivo del partido por el cual se había constituido en vicepresidente, al mismo tiempo que le permitió constituirse transitoriamente en el principal eje de la oposición al gobierno kirchnerista.

11. La categoría "Mayoría Moral" remite indefectiblemente a los grupos de presión compuestos por sectores evangélicos conservadores que gravitaron en el escenario político norteamericano a partir de la década del ochenta. Articulados en torno a la figura de Jerry Falwell, estos sectores se proponían marcar la agenda de la gestión pública, evitando el avance de la regulación estatal en áreas consideradas sensibles. Conjuntamente con los grupos Voz Cristiana y Tabla Redonda Religiosa, Mayoría Moral conformó la Nueva Derecha Cristiana, un movimiento destinado a ser uno de los principales espacios productores de dirigentes y candidatos del partido republicano. Para un análisis del surgimiento de Mayoría Moral, ver Casanova (1994:206-207).

12. Como señala Hiller (2011), dicha estrategia combinaba dos recursos constitucionales diferentes: la iniciativa popular y el referéndum. El primero requiere de un número mínimo de firmas para proponer el tratamiento de un proyecto de ley ante el Congreso (art. 39 de la Constitución Nacional y Ley Nacional no 24.747). El referéndum remite a una consulta popular, vinculante o no, iniciada por alguna de las Cámaras o el Poder Ejecutivo (art. 40 de la Constitución Nacional y Ley Nacional no 25.432).

13. Se trató de un clivaje que ya había tenido sus primeras secuencias en 2003 y 2004 con los debates públicos sobre Unión Civil y Educación Sexual en la Ciudad Autónoma de Buenos Aires (Jones, Azparren y Polischuk, 2010). Estas iglesias subrayaron "la 
autonomía de la sociedad civil de cualquier teología particular para darse sus propias formas de organización y de consenso surgidos de la práctica democrática" (Iglesia Evangélica Luterana Unida, 2010) y que "un estado democrático y pluralista debe estar abierto a escuchar las voces de todos y a decidir con libertad" (Iglesia Evangélica Metodista Argentina, 2010).

14. La Comunión de las Iglesias de la Reforma, la Iglesia Evangélica Metodista Argentina (IEMA) y la Iglesia Evangélica Pentecostal Misionera (IEPM) respaldaron, mediante comunicados particulares, la posición adoptada por la federación que los nuclea, la FAIE, con la finalidad de robustecer la postura disonante en el debate del proyecto, tanto en el ámbito parlamentario como en el espacio público. El documento de la Comunión de las Iglesias de la Reforma remarcó las ambigüedades de la iniciativa en discusión, cuyas directrices representaban finalmente la consagración de una mayor desigualdad al interior del entramado de relaciones estatales-religiosas, y la erosión del ejercicio irrestricto de la libertad de opinión y praxis religiosa. Por su parte, la IEMA estableció directamente su oposición al proyecto Hotton, fundamentando que la plena libertad religiosa conlleva, necesariamente, la nulidad de los privilegios vigentes para una comunidad en particular: la católica.

15. Tras la acusación pública de Cynthia Hotton, las diputadas nacionales Elsa Álvarez, Elisa Carrió y Patricia Bullrich también manifestaron ante sus pares de la Cámara Baja y ante los medios de comunicación haber recibido ofertas de soborno a cambio de un voto positivo en el debate sobre la ley de presupuesto. Estas denuncias motivaron la organización de una comisión de investigación parlamentaria, presidida por la diputada Graciela Camaño, la cual finalmente desestimó las acusaciones por falta de pruebas.

16. Catterberg y Palanza (2012) identificaron tres ciclos políticos en la primera gestión política de Cristina Fernández de Kirchner en su relación con la opinión pública. El primer ciclo corresponde al período marzo 2008-fines de 2009, signado por el conflicto en torno a la resolución 125 y coronado con la derrota electoral de octubre de 2009. En ese momento también se produjo el ascenso mediático de Julio Cobos, como principal figura de la oposición al kirchnerismo, a raíz de su actuación en la citada controversia parlamentaria. El segundo ciclo se abre a principios de 2010, con la recuperación económica y cierra con la muerte de Néstor Kirchner en octubre del mismo año. Ambos fenómenos significaron un cambio en el humor político a favor de la gestión y la imagen de la presidenta. Finalmente, el tercer ciclo recorre el lapso comprendido entre noviembre de 2010 y octubre de 2011, donde la simpatía y la popularidad de Cristina Fernández de Kirchner se potenciaron, debido a la consolidación de las variables macro económicas, y se cristalizaron en una victoria contundente en los comicios de octubre de 2011. Este último escenario también significó la dilución definitiva de las posibilidades de figuras antagonistas al oficialismo, erosionadas frente a la recuperación del gobierno en la consideración de la opinión pública.

17. Además de Cynthia Hotton, la boleta publicitaria de VPMP difundió las candidaturas de: 1) Gisela Sawin, líder evangélica de la iglesia Catedral de la Fe, licenciada en periodismo y teología, y autora de libros y publicaciones religiosas, 2) Fernando Oltra Santa Cruz, abogado, católico y profesor en la UCA, y 3) Jorge Schiavi, líder evangélico en la iglesia Catedral de la Fe, licenciado en Organización de Producción (UADE) y empleado jerárquico en AFIP. Además de los datos sobre su adscripción religiosa y trayectoria profesional/académica, la publicidad también mencionaba el estado civil y la cantidad de hijos de cada candidato. 


\section{Marcos Carbonelli}

\section{BIBLIOGRAFÍA}

ABOY CARLÉS, Gerardo. (2001), Las Dos Fronteras de la Democracia Argentina. La Reformulación de las Identidades Políticas de Alfonsín a Menem. Rosario, Homo Sapiens.

ALGRANTI, Joaquín. (2010), Política y Religión en los Márgenes. Nuevas Formas de Participación Social de las Mega-iglesias Evangélicas en la Argentina. Buenos Aires, Ediciones Ciccus.

BOLTANSKI, Luc. (1990), El Amor y la Justicia como Competencias: Tres Ensayos de Sociología de la Acción. Buenos Aires, Amorrortu.

CASANOVA, José. (1994), Religiones Públicas en el Mundo Moderno. Madrid, PPC.

CATTERBERG, Gabriela; PALANZA, Valeria. (2012), “Argentina: Dispersión de la Oposición y el Auge de Cristina Fernández de Kirchner". Revista de Ciencia Política, vol. 32, no 1, pp. 3-30.

DOS SANTOS, Marcio; SCHWEIG, Graziele. (2004), “'Irmãos e Companheiros': A Campanha dos Candidatos da Igreja Universal nas Eleições 2004 em Porto Alegre". Debates do Ner, vol. 6, no 5, pp. 83-112.

DI STEFANO, Roberto; ZANATTA, Loris. (2000), Historia de la Iglesia Argentina. Desde la Conquista hasta Fines del Siglo XX. Buenos Aires, Mondadori.

DRI, Rubén. (1997), Proceso a la Iglesia Argentina. Relaciones de la Jerarquía Eclesiástica y los Gobiernos de Alfonsín y Menem. Buenos Aires, Biblos.

ESQUIVEL, Juan Cruz. (2004), Detrás de los Muros. La Iglesia Católica en Tiempos de Alfonsín y Menem (1983-1999). Bernal, Buenos Aires, Universidad Nacional de Quilmes Editorial.

HILLER, Renata. (2011), Conyugalidad y Ciudadanía: Disputas en torno a la Regulación Estatal de las Parejas Gay-Lésbicas en la Argentina Contemporánea. Tesis (Doctorado en Ciencias Sociales). Facultad de Ciencias Sociales, UBA, Buenos Aires.

JONES, Daniel; AZPARREN, Ana Laura; POLISCHUK, Luciana. (2010), “Evangélicos, Sexualidad y Política: Las Instituciones Evangélicas en los Debates Públicos sobre Unión Civil y Educación Sexual en la Ciudad Autónoma de Buenos Aires (2003-2004)", in J. M. Vaggione (comp.), El Activismo Religioso Conservador en Latinoamérica. Córdoba, Ferreyra Editor, pp. 193-248.

JONES, Daniel; CARBONELLI, Marcos. (2012), “Evangélicos y Derechos Sexuales y Reproductivos: Actores y Lógicas Políticas en la Argentina Contemporánea". Revista Ciências Sociais Unisinos, vol. 48, no 3, pp. 225-234.

GIUMBELLI, Emerson. (2002), O Fim da Religião: Dilemas da Liberdade Religiosa no Brasile na França. São Paulo, Attar.

LIPSET, Seymour; ROKKAN, Stein. (1967), “Cleavage Structures, Party Systems and Voter Alignments. An Introduction", in S. Lipset; S. Rokkan (orgs.), Party Systems and Voter Alignments: Cross National Perspectives. New York, Free Press, pp. 1-64.

MAURO, Sebastián. (2011), Representación e Identificaciones Políticas en Tiempos de Solidaridades Inestables (Ciudad Autónoma de Buenos Aires, 2001-2007). Tesis (Doctorado en Ciencias Sociales). Facultad de Ciencias Sociales, UBA, Buenos Aires. 
NOVARO, Marcos. (2000), Representación y Liderazgo en las Democracias Contemporáneas. Rosario, Homo Sapiens.

OLLIER, María Matilde. (2001), Las Coaliciones Políticas en la Argentina. El Caso de la Alian$z a$. Buenos Aires, Fondo de Cultura Económica.

ORO, Ari Pedro. (2003), “A Política da Igreja Universal e seus Reflexos nos Campos Religioso e Político Brasileiros". Revista Brasileira de Ciências Sociais, vol. 53, no 18, pp. 53-69.

SCHERLIS, Gerardo. (2009), "El Partido Estatal Estratárquico de Redes. Apuntes sobre Organización Política en la Era de los Partidos no Representativos", in I. Cheresky (comp.), Las Urnas y la Desconfianza Ciudadana en la Democracia Argentina. Rosario, Homo Sapiens, pp. 131-162.

SEMÁN, Pablo. (2000), A Fragmentação do Cosmos: Um Estudo sobre as Sensibilidades de Fiéis Pentecostais e Católicos de um Bairro da Grande Buenos Aires. Tesis (Doctorado en Antropología). Universidade Federal do Rio Grande do Sul, Porto Alegre.

WYNARCZYK, Hilario. (2006), Partidos Políticos Conservadores Bíblicos en la Argentina. Formación y Ocaso 1991-2001. Civitas-Revista de Ciências Sociais, vol. 6, no 2, pp. $11-41$.

(2009), Ciudadanos de Dos Mundos. El Movimiento Evangélico en la Vida Pública Argentina 1980-2001. Buenos Aires, Universidad Nacional de San Martín, UNSAM Edita.

(2010), Sal y Luz a las Naciones. Evangélicos y Política en la Argentina (1980-2001). Buenos Aires, Siglo XXI.

\section{Documentos Consultados}

Comunión de las Iglesias de la Reforma, "Sobre el Debate en el Congreso de la Nación en relación con la 'Ley de Libertad e Igualdad Religiosa'”, 28/9/2010. Disponible en: http:/ /www.iglesiaevangelica.org/men_hemosdicho.htm. Acceso en 30/12/2011.

Cynthia Hotton, "Carta a los Militantes de Valores para mi País", 12/7/2011, comunicación interna.

Federación Argentina de Iglesias Evangélicas, “No Hay Libertad Religiosa sin Igualdad Religiosa", 29/8/2010. Disponible en: http://faie.org.ar/Lineas\%20de\%20trabajo\%20pastoral\%20FAIE.pdf. Acceso en 30/12/2011.

Iglesia Evangélica Luterana de la Argentina, "Posición de la Iglesia Evangélica Luterana Argentina sobre el matrimonio homosexual", 2010. Disponible en: http:/ /www.sanlucas.org $/$ modules.php?name=News\&file=article\&sid=201. Acceso en 15/6/2013.

Iglesia Evangélica del Río de la Plata-Iglesia Evangélica Luterana Unida, "Declaración IELU-IERP sobre el Proyecto de Ley de Matrimonio entre Personas de un mismo Sexo", 31/5/2010. Disponible en: http://sexualidadyddhh.wordpress.com/ 2010/05/31/declaracion-ielu-ierp-sobre-el-proyecto-de-ley-sobre-matrimonio-entre-personas-de-un-mismo-sexo/. Acceso en 20/9/2013. 


\section{Marcos Carbonelli}

Iglesia Evangélica Metodista Argentina, 2010, “Declaración sobre la Ley de Matrimonio Igualitario". Disponible en: www.iglesiametodista.org.ar/v2/detalle.php?id_ nota $=28$. Acceso en 20/9/2013.

Iglesia Evangélica Metodista Argentina, 2011, “IEMA. Declaración Episcopal sobre la Ley de Cultos", 22/9/2010. Disponible en: http:/ /iemaentemperley.blogspot.com/ 2010/09/declaracionepiscopal-sobre-la-ley-de.html. Acceso en 30/12/2011.

Iglesia Evangélica Pentecostal Misionera, “Declaración de la Iglesia Evangélica Pentecostal Misionera", comunicación interna, septiembre 2010.

Prein, Guillermo, "Contra la libertad de cultos", 14/8/2010. Disponible en: http:/ / www.guillermoprein.com/2010/08/contra-la-libertad-de-culto_14.html. Acceso en 14/8/2012.

Proyecto de Ley de Libertad Religiosa (2010). Disponible en: http://www1. hcdn.gov.ar/proyxml/expediente.asp? fundamentos=si\&numexp=6879-D-2008. Acceso en 25/9/2013.

\section{Fuentes Periodísticas Consultadas}

Clarín, “¿Un pastor en la lista PRO de la ciudad?, 24/4/2009. Disponible en http:// www.clarin.com/diario/2009/04/24/elpais/p-01904718.htm. Acceso en 21/9/2013.

"Presiones en diputados: Hotton denunció a la diputada oficialista Fadel", 17/11/2010. Disponible en http://www.clarin.com/politica/Declaran-comisiondiputadas-denunciaron-presiones_0_373762816.html. Acceso en 24/9/2013.

El Cronista, "López Murphy, ahora porteño y cobista", 5/2/2010. Disponible en http:/ / www.cronista.com/impresageneral/Lopez-Murphy-ahora-porteo-y-cobista-20100205-0025.html. Acceso en 21/9/2013.

La Nación, "Avanza la despenalización del aborto", 10/11/2008. Disponible en http:// www.lanacion.com.ar/1068359-avanza-la-despenalizacion-del-aborto. Acceso en 20/9/2013.

"El derecho de los niños a tener padre y madre. Por Cynthia Hotton", 20 /4/2010. Disponible en http:/ / www.lanacion.com.ar/1256259-el-derecho-de-los-ninos-a-tener-madre-y-padre. Acceso en 21/9/2013.

, "Matrimonio gay: campaña en colegios", 1/7/2010. Disponible en: http:// www.lanacion.com.ar/1280435-matrimonio-gay-campana-en-colegios. Acceso en 22/9/2013.

,"Hotton, candidata de los valores", 7/7 / 2011. Disponible en http:/ / www.lanacion.com.ar/1387515-hotton-candidata-de-los-valores. Acceso en 21/9/2013.

Noticias Urbanas, "Cynthia Hotton, PRO Evangélica", 9/4/2009. Disponible en http: / / www.noticiasurbanas.com.ar/info_item.shtml?sh_itm=a9f45eaa1 30dfbb69aeacd936d24c1f6. Acceso en 21/9/2013.

Página 12, "La diputada que dio el mal paso", 19/11/2010. Disponible en http:/ / www.pagina12.com.ar/diario/elpais/1-157146-2010-11-19.html. Acceso en 22/9/2013. 
Perfil, "Cynthia Hotton: 'Cobos es el garante del gobierno'”, 14/10/2008. Disponible en http://www.perfil.com/contenidos/2008/10/14/noticia_0023.html. Acceso en 24-09-2013.

Pulso Cristiano 2, "Mi hermano ¿mi candidato?", 9/10/2003. Disponible en http:/ / www.pulsocristiano.com.ar/. Acceso en 27/9/2013.

Pulso Cristiano 118, "Dos diputados evangélicos se oponen a beneficios sociales para parejas del mismo sexo", 4/9/2008. Disponible en http://www.pulsocristiano. com.ar/newss/pulso118.html. Acceso en 20/9/2013.

Tiempo Argentino, “Cynthia Hotton: 'Cobos no es ni Chacho ni Scioli'”, 25/11/2008. Disponible en http://tiempoargentino.blogspot.com.ar/2008/11/cynthia-hotton-cobos-no-es-ni-chacho-ni.html?m=0. Acceso en 25/9/2013.

, "Los antiabortistas arman una red 'para no perder la guerra'", 6/10/2010. Disponible en http://tiempo.infonews.com/notas/los-antiabortistas-armanuna-red-nacional-para-no-perder-guerra. Acceso en 26/9/2013. 


\section{RESUMO}

Valores para mi País: Evangélicos na Esfera Política Argentina (2008-2011)

Este artigo analisa a atuação do partido evangélico "Valores para mi País" na esfera política argentina no período 2008-2011. O foco central é examinar seu projeto de se constituir em um espaço de representação dos grupos pluriconfessionais. Utilizam-se fontes metodológicas diversas (entrevistas, análise de materiais do partido, etnografia de reuniões e acompanhamento de suas marchas) para reconstruir suas iniciativas políticas, suas alianças e antagonismos, sua participação em controvérsias públicas e seu desempenho na arena eleitoral. Embora esta formação política tenha apresentado inovações significativas diante de seus antecessores, explicitaremos também as razões de seu fracasso, devido a erros táticos e à vigência das identidades partidárias na Argentina.

Palavras-chave: evangélicos; política; Argentina; valores; representação

\section{ABSTRACT \\ Valores para mi País: Evangelicals in the Argentinian Political Sphere (2008-2011)}

This article analyzes the actions of the evangelical party "Valores para mi País" in the Argentinian political sphere between 2008 to 2011. The main focus is to examine its project of establishing itself in a space in which multiple confessions are represented. Several methodological sources were employed (interviews, analysis of party documents, ethnographies of meetings and marches) in order to reconstruct their political initiatives, their alliances and antagonisms, their participation in public controversies and their performance in the electoral arena. Although this political formation presents significant innovations compared to predecessors, we will also point out the reasons for its failure, due to tactical errors and the reality of party identities in Argentina.

Keywords: evangelicals; politics; Argentina; values; representation 


\section{RÉSUMÉ}

Valores para mi País: Les Évangéliques dans la Sphère Politique Argentine (2008-2011)

Cet article analyse le parcours du parti évangélique "Valores para mi País" sur la scène politique argentine de 2008 à 2011. Il s'agit avant tout d'examiner son projet de constituer un espace de représentation pour des groupes pluriconfessionnels. Nous nous sommes appuyés sur diverses ressources méthodologiques (entretiens, analyse des documents du parti, ethnographie des réunions et suivi des manifestations) pour reconstruire ses initiatives politiques, ses alliances et ses antagonismes, sa participation au débat public et ses performances électorales. Bien que cette formation politique ait fait montre d'innovations significatives par rapport à ses prédécesseurs, nous expliquerons également les raisons de son échec, qu'elle doit entre autres à des erreurs tactiques et aux fortes identités partisanes encore en vigueur en Argentine.

Mots-clés: évangéliques; politique; Argentine; valeurs; représentation

\section{RESUMEN}

Valores para mi País: Evangélicos en la Esfera Política Argentina (2008-2011)

Este artículo analiza la actuación del partido evangélico "Valores para mi País" en la esfera política argentina en el período 2008-2011. El eje central es examinar su proyecto de constituirse en un espacio de representación de los grupos pluriconfesionales. Se utilizan fuentes metodológicas diversas (entrevistas, análisis de materiales del partido, etnografía de reuniones y seguimiento de sus marchas) para reconstruir sus iniciativas políticas, sus alianzas y antagonismos, su participación en controversias públicas y su desempeño en la arena electoral. Aunque esta formación política haya presentado innovaciones significativas frente a sus antecesores, explicitaremos también las razones de su fracaso, debido a errores tácticos y a la vigencia de las identidades partidarias en la Argentina.

Palabras clave: evangélicos; política; Argentina; valores; representación 